Article

\title{
A Smart City Application: A Fully Controlled Street Lighting Isle Based on Raspberry-Pi Card, a ZigBee Sensor Network and WiMAX
}

\author{
Fabio Leccese *, Marco Cagnetti and Daniele Trinca \\ Dipartimento di Scienze, Università degli Studi "Roma Tre", Via della Vasca Navale 84, Rome 00146, \\ Italy; E-Mails: ing.marco.cagnetti@gmail.com (M.C.); cico80@gmail.com (D.T.) \\ * Author to whom correspondence should be addressed; E-Mail: leccese@uniroma3.it; \\ Tel.: +39-06-5733-7347.
}

External Editor: Antonio Puliafito

Received: 27 October 2014; in revised form: 5 December 2014 / Accepted: 12 December 2014 / Published: 18 December 2014

\begin{abstract}
A smart city application has been realized and tested. It is a fully remote controlled isle of lamp posts based on new technologies. It has been designed and organized in different hierarchical layers, which perform local activities to physically control the lamp posts and transmit information with another for remote control. Locally, each lamp post uses an electronic card for management and a ZigBee tlc network transmits data to a central control unit, which manages the whole isle. The central unit is realized with a Raspberry-Pi control card due to its good computing performance at very low price. Finally, a WiMAX connection was tested and used to remotely control the smart grid, thus overcoming the distance limitations of commercial Wi-Fi networks. The isle has been realized and tested for some months in the field.
\end{abstract}

Keywords: control systems for smart grids; lighting system; wireless networks for smart grids; ZigBee; sensors; Raspberry-Pi; ARM processor

\section{Introduction}

The Smart City (SC) paradigm helps renovate the traditional city concept. In fact, it is possible to realize and develop efficient demand-side strategies integrating the monitoring and automation features 
ensured by intelligent devices and their communication apparatuses typically used in many applications. Within this concept, public lighting, being a great electrical energy consumer, has recently been attracting the interest of the research community. Scientists, combining the SC paradigm with alternative energies and new lighting technologies, are conceiving systems previously unimaginable, which can increase the efficiency obtaining considerable energy consumption savings and consequently money savings [1-4].

This article shows how an isle of lamp posts, used to light a crossroad and placed in an area not reached by ADSL lines and $3 \mathrm{G}$ signals, can be much more efficiently managed by applying the smart city principles. The realized application changes the way of conceiving the isle: sensing the transit of a car approaching the crossroad and controlling it by an efficient management strategy, a typical power grid, like the isle of the lamp posts, is transformed in a smart city application.

The goal is obtained combining an efficient management strategy with new technologies. The strategy divides the complex structure of the isle into layers which are linked by communication layers. Each layer uses innovative technologies to make possible the application of the smart city principles. For example the lamp post exploits some innovative technologies both for the supply (photovoltaic panel) as well as for the control (ZigBee network and RaspBerry-Pi). Moreover, to provide a robust system also able to face and overcome the absence of Asymmetric Digital Subscriber Line (ADSL) or 3rd Generation (3G) communication, that in some parts of the city might not available, we used WiMAX technologies that allowed us to fully control the isle from a remote station.

The choice to test our system in this application is strongly joined to the road safety problem. In fact, the lighting of crossroads is fundamental to ensure the good night vision of typically hazardous points of the road where fatal crashes often happen. Based on this application, an economical analysis has also been realized to show how after the breakeven point is achieved, the system is more convenient with respect to older technology.

\section{State of the Art}

In this area, the efforts are focused on the use of alternative energies for the power supply of new lighting technologies [5-7], which allow obtaining considerable energy savings. Within lighting technologies, Light Emitting Diodes (LEDs) assure the possibility of switching on the lamp without the preheating typical of halogen ones; a very high lighting efficiency; low power consumption; a superior life time and quick switching times not comparable to those of older technologies (only incandescent lights have a lower lighting time, but with very big power consumption and the shortest time life); less sensitivity to transient phenomena, which have a big impact on other technologies, allowing thousands of lightings without the risk of lamp failure. These innovative characteristics allow development of a new remote-control system based on intelligent lamp posts that also send information to a central control system in order to simplify management and maintenance issues [1-4] also using holistic and bottom-up design strategies [1]. Within these researches, a relevant topic is the use of new sensor networks (wireless and not) and communication technologies, both to locally manage the lamp posts, but also sensor networks, and to send data towards a remote center [1-5,8-17].

Based on the best technologies and on the SG paradigm, our proposal describes a solution for an extremely diffused hostile scenarios, often neglected by the municipalities, but which have an enormous 
social relevance, and where both the mains and the internet signal provided by the most diffused communication technologies (ADSL and 3G) are not available.

\section{The Layers Architecture}

The architecture of the system has been conceived as a hierarchical layers structure for the full control of "unities" made up of sensors, actuators and local control cards. Each layer performs some control activities and transmits information to the other layers. The architecture foresees three layers called apparata, local control and remote control.

In the "apparata layer" we consider all the hardware and software designed for the autonomous and automatic control of the single apparatus or unit. This layer communicates with the higher one and vice versa using a ZigBee mesh wireless tlc network particularly suitable for closed devices and low bit rates [3]. The local control unit collects the data received from the single units to check their activity and functionality. It is realized with a RaspBerry-Pi control card, which collects and locally elaborates data from the single apparatus verifying that there are no problems. If a problem(s) occurs, the card sends an error message on the internet exploiting the upper layer. The latter is realized with a WiMAX trans-receiver, which is connected, via radio link, to the World Wide Web. Figure 1 shows the architecture of the system.

Figure 1. Block scheme of the system architecture.

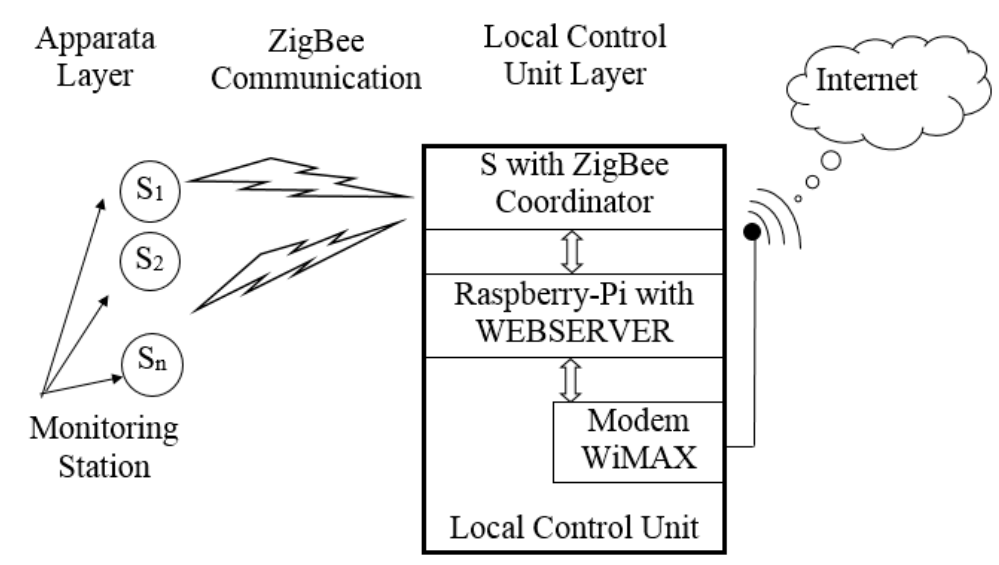

\section{Technologies and Devices}

Before analyzing the realized application, the three technologies and devices used in this work are briefly described.

\subsection{ZigBee}

ZigBee is a standard for wireless communication based on the IEEE 802.15.4 protocol. It is used to connect several devices together creating a mesh network with no central powerful device, but with distributed nodes able to transfer data throughout intermediate motes. Table 1 shows a comparison between the most famous technologies used as wireless communication. As the table shows, both Wi-Fi and the Bluetooth have higher bit rates than ZigBee, but the higher power consumption and the 
lower number of devices making up the network suggest that the ZigBee technology is the best candidate to create sensor networks for applications where the power consumption must be as low as possible. Furthermore, studies proved that the ZigBee is more affordable in terms of power consumption and costs than competitive technologies [3,18-20].

Table 1. ZigBee vs. some other wireless network.

\begin{tabular}{cccc}
\hline & ZIGBEE & WI-FI & BLUETOOTH \\
\hline IEEE standard & 802.15 .04 & $802.11 \mathrm{~b} / \mathrm{g}$ & 802.15 .01 \\
Main application & Control & Broadband & Mobile devices \\
Number of network & Up to 65,000 & 32 & 7 \\
devices & $20-250 \mathrm{~kb} / \mathrm{s}$ & $11 / 54 \mathrm{Mb} / \mathrm{s}$ & $720 \mathrm{~kb} / \mathrm{s}$ \\
Bit rate & $100 \mathrm{~m}$ & $100 \mathrm{~m}$ & $10 \mathrm{~m}$ \\
Range & $100-1000$ days & $1-5$ days & $1-7$ days \\
Battery life & & &
\end{tabular}

The communication between the lamp posts in the isle has been achieved using the ZigBee standard. This uses a mesh topology with a coordinator, routers (also called primary) and end device nodes (also called secondary); the first controls the formation and security of networks, the second extend the range of networks while the last perform specific sensing or control functions. Each lamp post has a Tx/Rx to get or send information and control commands. Furthermore, the lamp posts closer to the roads, used to approach the intersection, are also connected to a presence sensor card. The secondary nodes will send their status to the coordinator lamp post throughout the mesh network and receive back commands. Thus, the power consumption is limited to short time frames, since there is no continuous communication between nodes.

The networked communication is realized using the XBee radio modules by MaxStream which are already equipped with on-chip antenna [21-23]. These modules have been chosen because they have a good operational range for the application reaching tens of meters indoors and hundreds of meters outdoors. Thanks to its high radio sensitivity the XBee module has a low probability to receive corrupted packets (less than 1\%). Furthermore the reported tests demonstrated that these performances are achieved without sacrificing power consumption. In fact, the current necessary to operate the two-way radio transmissio, is approximately $50 \mathrm{~mA}$ with a $3 \mathrm{~V} \mathrm{DC}$ source. To ensure further power reduction, the sleep mode ensures a current draw of less than $10 \mu \mathrm{A}$.

\subsection{RaspBerry-Pi}

The role of the Coordinator Lamp Post is to integrate the computing part of the system. For this aim, the Raspberry-Pi card (or Pi following) has been adopted which ensures high computing power and interconnectivity with other devices such as the WiMAX modem [24-27].

Raspberry-Pi is a low-cost $(\approx 25 €)$ basic computer contained on a credit-card size circuit board and featuring ports for HDMI, USB 2.0, composite video, analog audio, power, Internet and SD card. The computer runs entirely on open-source software and is able to run several applications such as: spreadsheets, word-processing, games, and high-definition video playback. 
Other devices, as ARDUINO [28] or Beaglebone [29] could be used; Table 2 shows some principal characteristics of these devices. As usual, choosing which board you want depends on the type of intended project, and one's programming experience. If one wants to create a hardware project then the Arduino is by far the best choice. The analog inputs and PWM outputs add a whole spectrum of compatibility the Pi cannot provide natively. In addition, the large about of $\mathrm{I} / \mathrm{O}$ pins let one connect multiple sensors and feedback components. The Arduino however is not as powerful as the Pi, so it has no proper audio, video or internet out-of-the-box (you can however add basic functionality for this). The Arduino can send data to a PC or Pi, over serial connections, and one can then create a program to read this data and do something useful.

If one wants to create a software project then the Pi and the Beaglebone are the way to go. The audio, video and internet capabilities make them the winners in this aspect. There is no need to attach external components, so there is no real need to learn electronics and they have the possibility to easily drive both $3 \mathrm{G}$ modems and WiMAX ones. Among them, the lower power consumption and lowest cost favor the RaspBerry-Pi, making it the best candidate for SC applications.

Table 2. Raspberry-Pi vs. Arduino and Beaglebone.

\begin{tabular}{cccc}
\hline & RaspBerry & Arduino & Beaglebone \\
\hline Base Price in US \$ & 25 & 35 & 50 \\
\hline Power Draw & $\sim 150 \mathrm{~mA} \mathrm{@} \mathrm{5V}$ & $\sim 50 \mathrm{~mA} \mathrm{@} \mathrm{5V}$ & $\sim 250 \mathrm{~mA} @ 5 \mathrm{~V}$ \\
\hline Operating System & Linux & Custom & Linux \\
\hline Suited for & Software & Hardware & Software \\
\hline Number of I/O pins & 8 Digital & $\begin{array}{c}\text { 14 Digital (6 PWM) } \\
6 \text { analog }\end{array}$ & 65 Digital \\
\hline Peripherals & $\begin{array}{c}\text { 2 USB Hosts, } \\
\text { Micro-USB Power, } \\
1 \text { 10/100 Mbps } \\
\text { Ethernet }\end{array}$ & None & $\begin{array}{c}\text { 1 USB Host, 1 Mini-USB } \\
\text { Client, } 110 / 100 \text { Mbps } \\
\text { Ethernet }\end{array}$ \\
\hline Internet & Yes & Via Shield & Yes
\end{tabular}

The Raspberry is the hub of the system since it allows the visualization of the status of the entire lighting system. It is connected to the local monitoring station via the ZigBee network to manage the different lamp posts. Furthermore, it is able to receive information from the secondary lamp posts and from the presence sensor cards allowing monitoring the isle. Together, the Raspberry and the local monitoring station realize the Coordinator Lamp Post base control station, which receives information about the status of the lamp posts.

\subsection{WiMAX}

Worldwide Interoperability for Microwave Access (WiMAX) is the radio communication technology used to connect the Local Control Unit with the World Wide Web. It is based on the IEEE 802.16 standard, with the intent of deliver Internet connectivity to areas where a normal DSL service is still difficult and expensive to install or in parts of cities not reached by $3 \mathrm{G}$ signals $[5,30]$.

The reason for choosing WiMAX is that in some parts of the city, e.g., very far from the downtown, sometimes, there is very scarce penetration of telecommunication lines or of the radio communication 
coverage. In the best cases with clean line of sight (LOS) the radio link can cover up to $70 \mathrm{~km} \mathrm{[30].}$ Other technologies could be used to realize the remote communication such as $3 \mathrm{G}$, satellite communication, WiFi or ADSL, but, as Table 3 shows, none offer the specific abilities of WiMAX. Excluding ADSL that needs a cable whose placement could be extremely expensive in these areas, and WiFi whose coverage is extremely short (less than $100 \mathrm{~m}$ ), satellite communications offer worldwide coverage, but its subscription is usually much more expensive than a WiMAX or a 3G. The latter, always because is not profitable for the provider to create a $3 \mathrm{G}$ network, is not always active in these areas. For these reasons, WiMAX is a good candidate for this application. This would also allow diffusion of the SC paradigm in areas not properly considered as "city".

In our system, we installed a base station (BS), spreading WiMAX single carrier TDD service at $3.4845 \mathrm{GHz}$ center frequency and a bandwidth of $10 \mathrm{MHz}$. The BS transmitting antenna is an Argus tilt panel antenna model SPPX310M (65 deg Horizontal cut, 6.5 deg Vertical cut) [31].

Table 3. WiMAX vs. other communication technologies.

\begin{tabular}{|c|c|c|c|c|c|}
\hline & WiMAX & ADSL & WiFi & $3 G$ & $\begin{array}{c}\text { Satellite } \\
\text { Communication }\end{array}$ \\
\hline Wireless? & Yes & No & Yes & Yes & Yes \\
\hline $\begin{array}{l}\text { Distance } \\
\text { Covered }\end{array}$ & $\begin{array}{c}\text { Up to } 70 \mathrm{~km} \text { from } \\
\text { the } \mathrm{CPE}\end{array}$ & $\begin{array}{l}\text { Everywhere } \\
\text { with cable }\end{array}$ & $\mathrm{Up}$ to $100 \mathrm{~m}$ & $\begin{array}{c}\text { Up to } 5 \mathrm{~km} \text { from } \\
\text { the } \mathrm{BS}\end{array}$ & $\begin{array}{c}\text { Everywhere the } \\
\text { signal satellite is on }\end{array}$ \\
\hline $\begin{array}{l}\text { Subscription } \\
\text { Costs }\end{array}$ & About $20 €$ & About $20 €$ & About $20 €$ & About $20 €$ & About $100 €$ \\
\hline $\begin{array}{l}\text { Availability } \\
\text { in rural area }\end{array}$ & Medium/High & No & No & Medium & Yes \\
\hline
\end{tabular}

The total transmission power is $55 \mathrm{dBm}$ EIRP given by the output signal of $37 \mathrm{dBm}$ and an antenna gain of $18 \mathrm{dBi}$. The antenna was placed on the roof of a building at $30 \mathrm{~m}$ from ground level. To communicate between the main lamp post and the BS, we used a Huawei branded HES-319M outdoor WiMAX Customer Premise Equipment (CPE) [32], equipped with a $3.5 \mathrm{GHz} 45^{\circ}$ Cross-Polarization built-in directional antenna, with a maximum power at antenna port of $26 \mathrm{dBm}$ and $14 \mathrm{dBi}$ antenna gain. This allowed us to send reliably data at high speed. Furthermore, it avoids any type of interference with the ZigBee standard due to its different operating frequency.

The WiMAX module uses 64QAM5/6 modulation for the downlink when the CINR is higher than $30 \mathrm{~dB}$ and 16QAM3/4 for the uplink [33,34]. Instead, when the CINR is lower than $10 \mathrm{~dB}$, the link was still possible, but using a QPSK1/2 modulation because it is more robust at higher noise levels.

The CPE is Power over Ethernet (PoE) $802.3 \mathrm{a} / \mathrm{f}$ compliant and it runs at 48 VDC, so a DC-DC step-up boost has been required to make the CPE working in our system. We used a LTC3863 mounted on its demonstration circuit $1286 \mathrm{~A}$ in order to boost up the $12 \mathrm{~V}$ from solar panel to the $48 \mathrm{VDC}$ needed at the CPE PoE connector.

\section{The Application}

To widely test the idea, an isle of lamp posts, as shown in Figure 2, has been designed and realized. 
Figure 2. Schematic image of the on street system.

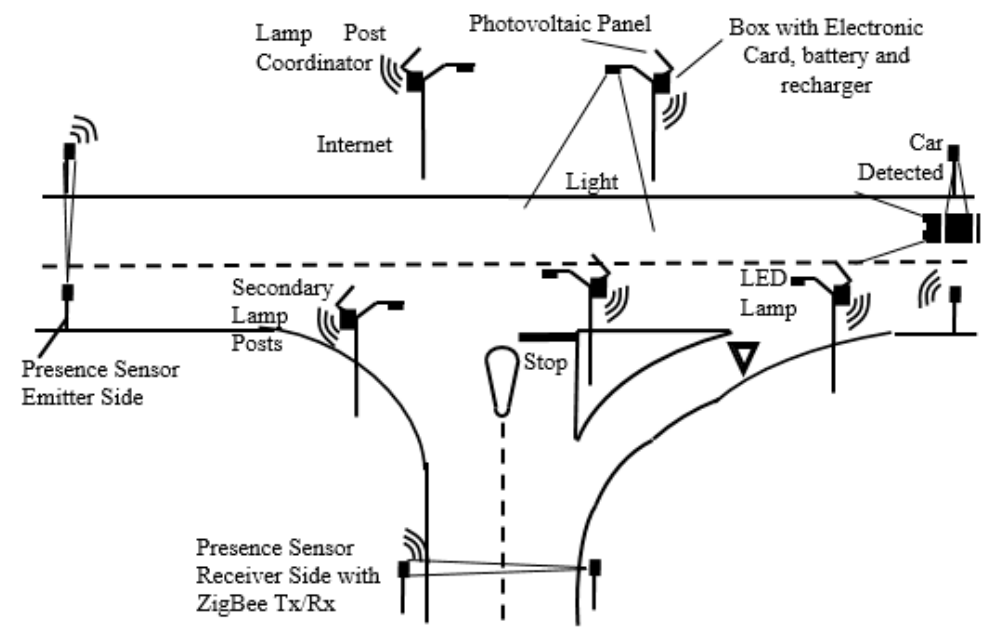

Through a flowchart, Figure 3 shows the management strategy of the isle.

Figure 3. Management strategy of the Smart Grid.

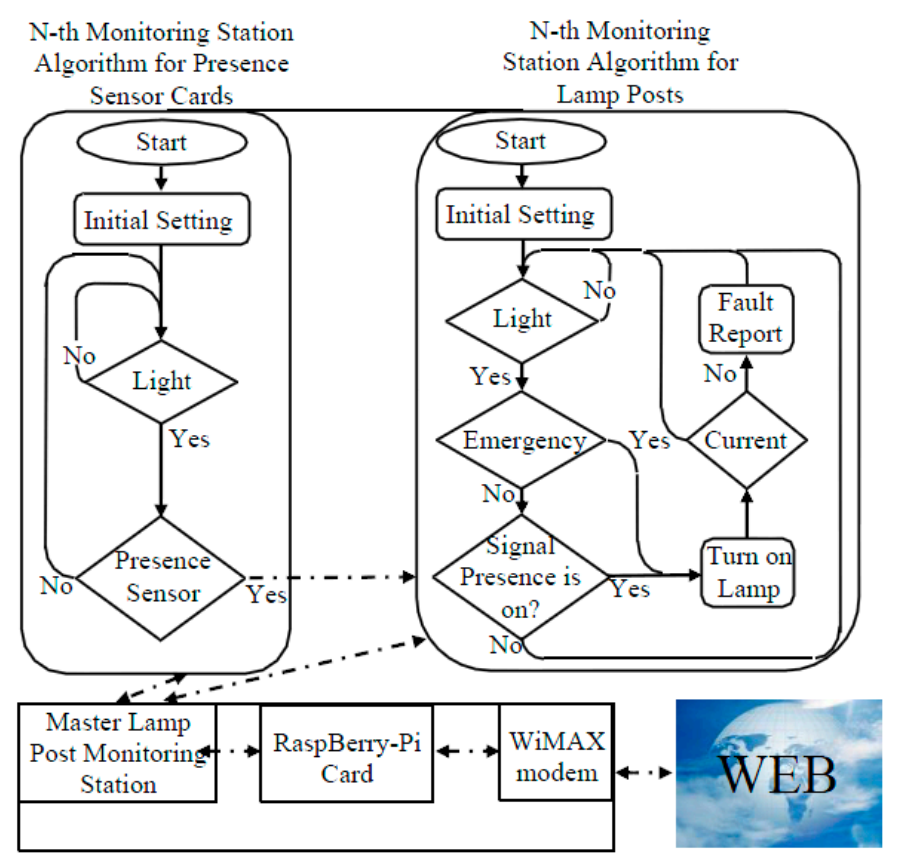

The electronic card checks if the sunlight is lower than a fixed limit [3]; in this case, it waits until the sensors signal the presence of a car or a pedestrian. When this happens, the control unit switches on the light for a fixed time, the current sensor starts the measurements and, in case of a fault detection, an alarm is sent to the master lamp. If no fault is detected, the microcontroller stores the current values. During the night the Coordinator Lamp Post requests data from the secondary lamp posts and makes them available on the Internet. In the case of people in difficulty, which need light for their activities, they will be able to switch on the lights by pressing one of the emergency buttons located in specific locations at the crossroad. The electronic card, also called monitoring station, is used in two versions: 
the first detects the presence of a vehicle and is called Presence Sensor Electronic Card, while the second manages the lamp post and is called Monitoring Station for Lamp Posts.

The first are placed near the road at about $45 \mathrm{~m}$ from the crossroad. They are enabled when the sunlight is lower than a fixed limit. They read a photoelectric sensor and if its light beam is interrupted by the passage of a car, the control card sends a wireless signal to the isle of lamp posts by the ZigBee network. When this signal is received by the Monitoring Stations for Lamp Posts and it are equipped with a ZigBee Tx/Rx, they switch on the light.

The monitoring station is realized with the use of a PIC $16 \mathrm{f} 688$ microcontroller that also manages the wireless transmissions. The lamp post management is thus realized, but for intelligent management, the maintenance needs require a wider and deeper control of the lamp posts. To meet these requests, a current sensor, directly mounted on the lamp posts and read by the Monitoring Station, provides information about lamp post activity and power consumption. This information is stored in the PIC memory and, if requested by the next layer, is sent to it.

The second layer communicates with the first layer by the ZigBee network and collects data coming from each lamp post. The collected data are then available for the analysis of power consumption and for monitoring the lamp activity. Obviously, if the n-lamp post does not communicate or sends wrong data, this layer will send an intervention request toward a remote operator to solve the problem.

The second layer uses a RaspBerry-Pi card [24-27]. This is placed only in a lamp post called Coordinator, (another lamp post equipped with the RaspBerry-Pi may cause redundancy) and it is connected to the lamp post Monitoring Station. The latter makes possible the communication between the RaspBerry-Pi and the other lamp posts realizing the communication between the second and the first layer. The RaspBerry-Pi plays a role of webserver collecting data from each lamp post and displaying them. The third layer uses the RaspBerry-Pi to send these data to the World Wide Web. A graphical interface (Figure 4) shows the information on the lamp posts' activities.

Figure 4. Lamp control system GUI and measurement of power consumption.

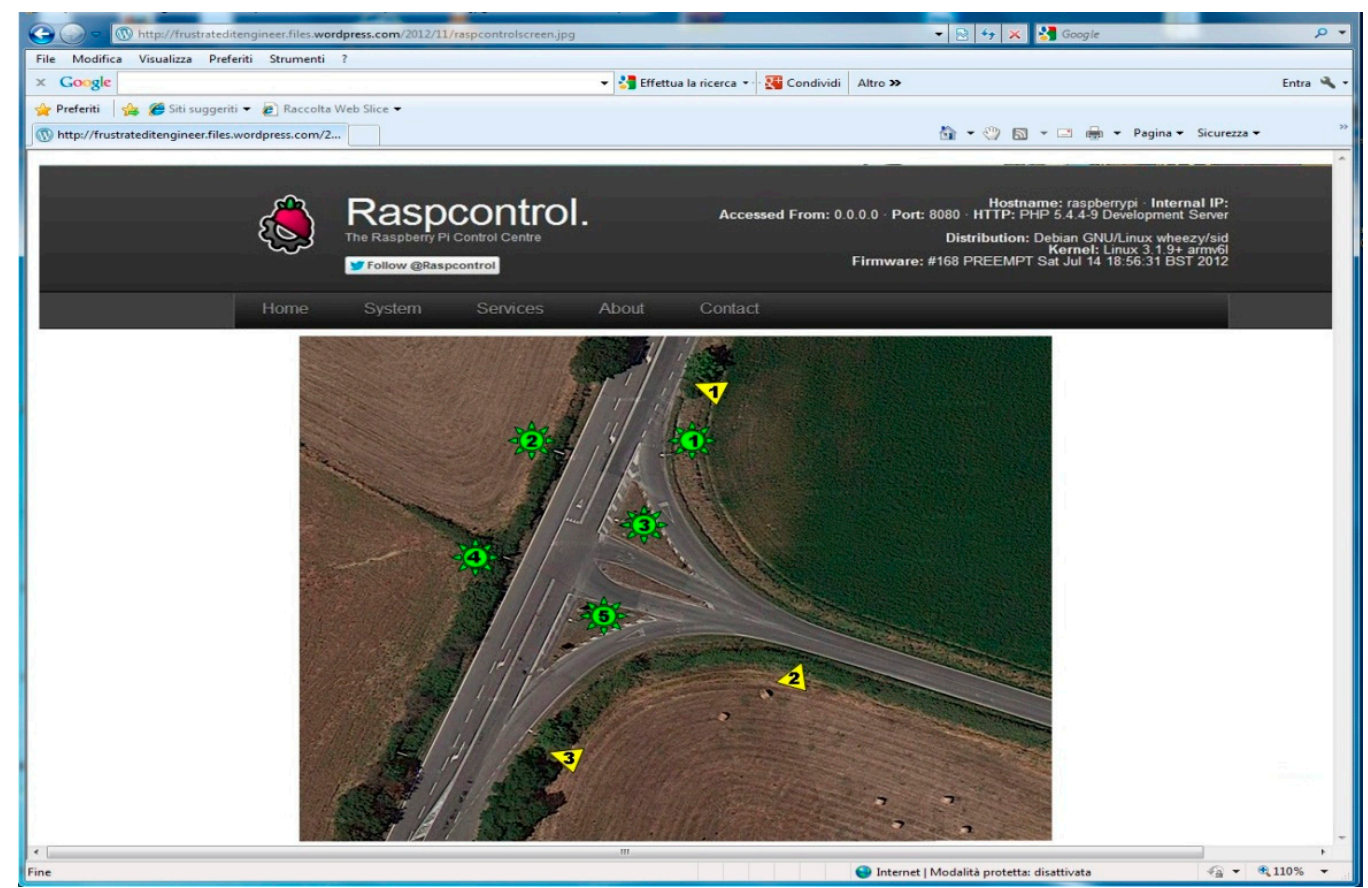


All this makes possible an easy control of the lamp posts from a remote station and can allow an easy scheduling of any maintenance actions by the service engineer. Figure 5 shows the system placed in a shelter for laboratory tests.

Figure 5. The system placed in a shelter for laboratory tests.

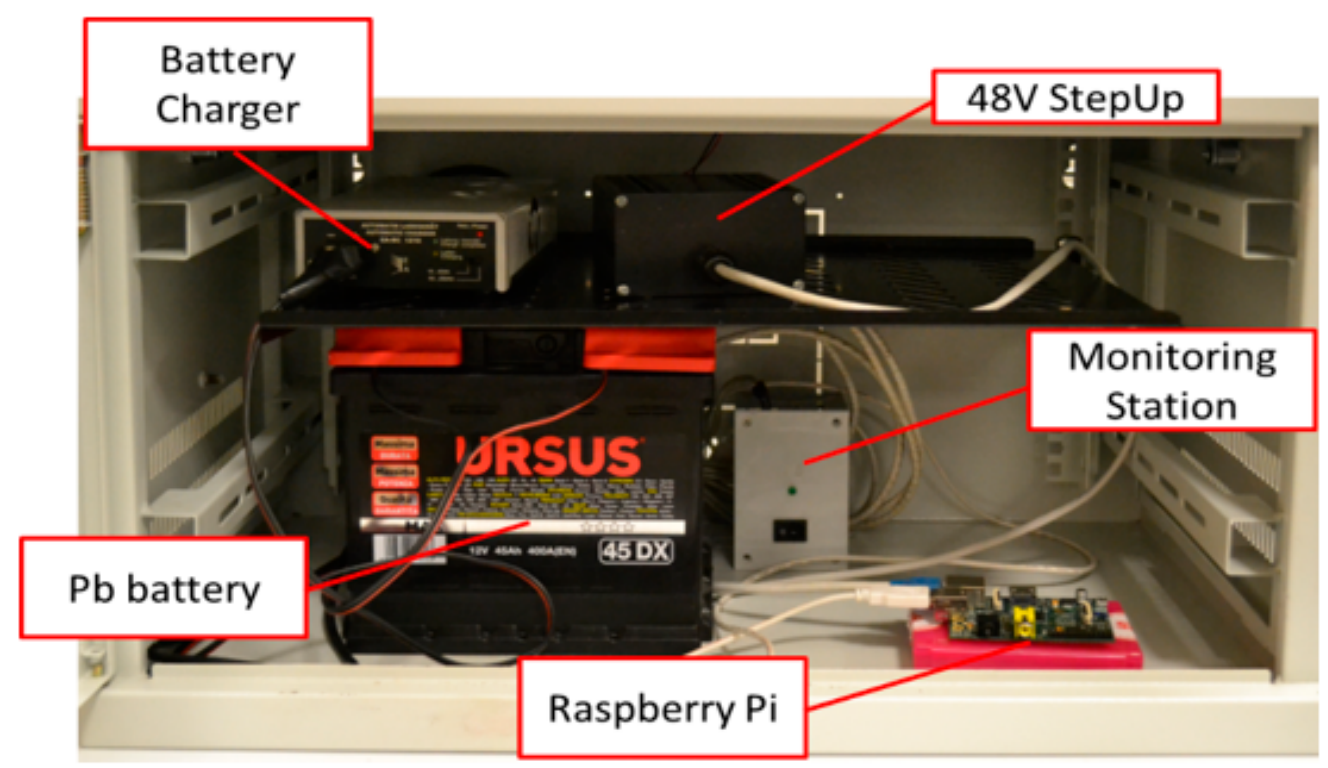

Figure 6 shows the operational test system working in real conditions.

Figure 6. Test system in the field.

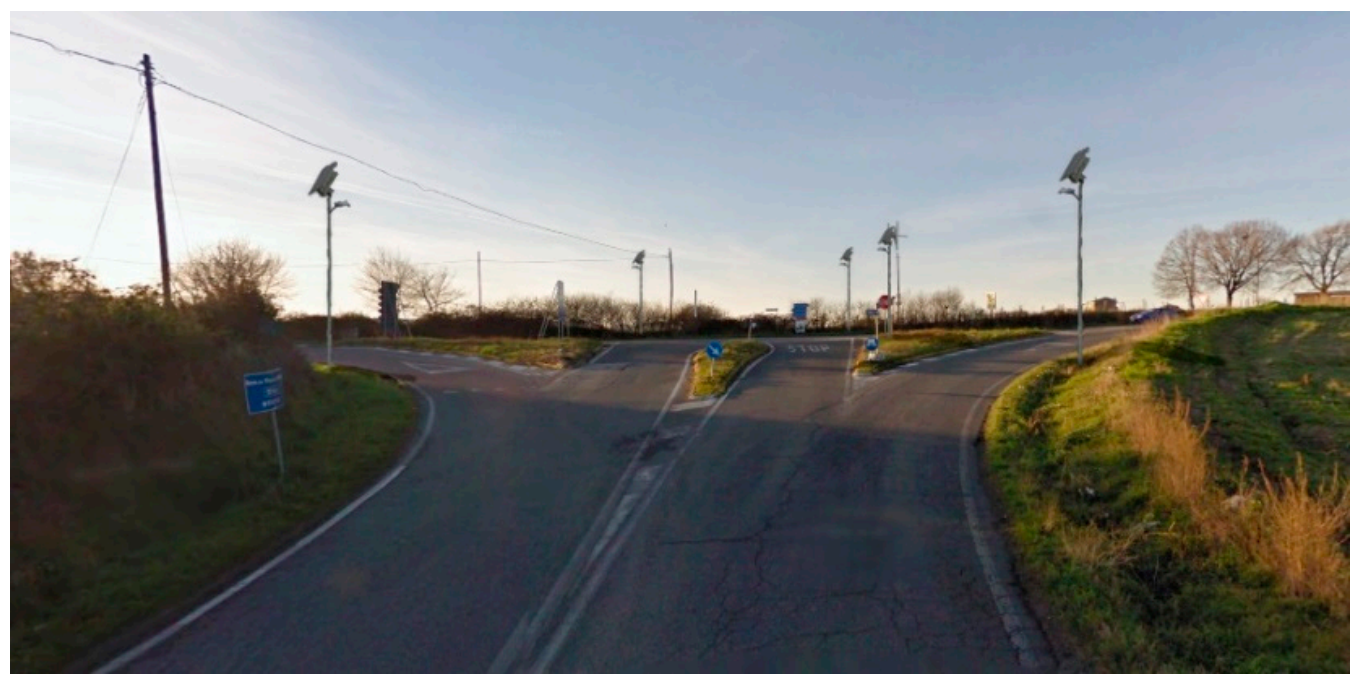

\section{The Lamp Post}

The lamp posts use, as new technologies, Light Emitting Diodes (LEDs) for the illuminating lamps and photovoltaic energy (PV) to supply the power. The use of these technologies is known in the literature, but a preventive traffic study allowed precisely defining the load allowing the correct dimensioning of the PV elements size. 
The choice to supply the lamp posts of an alternative energy source is imposed by the absence of mains in the area where the isle is placed, and strongly suggests the use of this kind of energies in areas where the mains is far away. In fact, it would be very expensive (requiring copper wires and civil engineering works) to connect the area. Among the alternative energies, the absence of a constant wind, suggested to us that the best alternative energy to use is the photovoltaic one. PV systems are composed of a PV panel, a battery and a battery recharger [35].

The choice of the PV elements' size has been studied to match the operative conditions of the lamp posts. To evaluate the load, a preventive check of the car transit along the street has been made for four months during winter and spring when the nighttime has a longer duration. Every night we registered an average passage of about one hundred cars, often passing in group of two-four cars each time. For each transit of cars, we fixed $30 \mathrm{~s}$ for the lighting of the lamps so, the worst case provides that the total time the lamps need to be lit every night is about $25 \mathrm{~min}$. Considering also anticipated some emergency situations, our system provides energy for one hour and a half. We also considered natural and weather conditions; in fact, we chose a larger battery to compensate for low sunlight for several days. Considering the loads, we have three different combinations:

(1) for the presence sensor card ( 0.2 A current consumption) the battery has a capacity of 6 Ah and the PV panel has a maximum power of $9 \mathrm{~W}-12 \mathrm{~V}$; this assures a functioning of $10 \mathrm{~h}$ for three consecutively nights;

(2) secondary lamp posts use a $19 \mathrm{~W}-12 \mathrm{~V}$ PV panel and a battery of 10 Ah capacity able to ensure two hours per night of use for three consecutively nights;

(3) the coordinator lamp post has higher a consumption than the secondary ones because it has also the Raspberry-Pi (current consumption $0.5 \mathrm{~A}$ ), which must be always connected to the Internet during the night and the WiMAX modem/router, which is activated only for two times during the night 15 min every time. To limit the consumption, the lamp section is managed like the secondary lamp posts, so the PV panel has a peak of $95 \mathrm{~W}-12 \mathrm{~V}$ and the battery a capacity of 48 Ah which assures an activity of 2 hours/night and the full activity for the hub for three consecutive nights. The modem average power consumption is about $20 \mathrm{~W}$.

Obviously, the consumption, and consequently the PV panels, the batteries' sizes and the costs, would be at least three times higher without the intelligent management system; moreover, the lower weight produces less stress on the mounting poles.

\section{Tests and Results}

The system has been realized and tested in the field for some months to verify the overall functionality under variable real-life conditions. The measurements allowed us to calculate energy and cost savings compared to other older technologies.

\subsection{Range Tests}

The article [3] has shown the reliability of the communication between two or more ZigBee modules under different environmental conditions is satisfactory. Nevertheless, following the procedure shown in [3], we performed some tests directly in the field where the lamp posts and the presence sensors are in line of sight (maximum distance about $45 \mathrm{~m}$ ). Standard Xbee modules with patch antenna from 
Digi-MaxStream have been used because from datasheet [21] and from [3] they seemed to satisfy the range needs.

According to [3], we perfomed several tests, each one foreseeing 10,000 transmissions both during clear weather and during rain. Using an appropriate adapter to simulate the retransmission and using the X-CTU software provided by Digi-MaxStream, we checked the transmissions verifying that the test packetd, sent through the network by an Xbee module, arrived at the coordinator lamp and were correctly returned back. Using the minimum transmission power available, we obtained the results reported in Table 4 , with an average reliability of $100 \%$.

Table 4. ZigBee reliability tests.

\begin{tabular}{ccc}
\hline \multicolumn{3}{c}{ XBEE STANDARD-Patch Antenna } \\
\hline & Sunny & Rainy \\
\cline { 2 - 3 } & up to $\mathbf{4 5} \mathbf{~ m}$ & up to $\mathbf{4 5} \mathbf{~ m}$ \\
\hline No obstacles & $100 \%$ & $100 \%$ \\
\hline Vegetation & $100 \%$ & $100 \%$ \\
\hline
\end{tabular}

\subsection{Local Transmission Tests}

Other tests have been designed and realized to verify the overall communication ability between the coordinator, the secondary lampposts, and Internet. The first test verified how the system reacts when there is a fault in a lamp post or a presence sensor. Simulating the absence of one of them the hub software alerts of the malfunction on its graphical interface.

The second test verifies the case of break-downs of the coordinator lamp post. If the fault is either on the electrical section or in the local communication section, the hub software again shows the problem. Instead, if the fault is either on the RaspBerry-Pi card or on the WiMAX section, the impossibility to connect to the website means either breakage or theft. A secondary coordinator, activated on another lamp, could solve this problem.

\subsection{WiMAX Test}

The previously described WiMAX system was used to perform several reliability tests of the WiMAX technology. Due to the decay of the signal intensity with the increase in the working distance or with the presence of obstacles leading to multi-path fading, the IEEE 802.16.1 standard [36] does not provide any data on the distance achievable with WiMAX devices.

Because our goal is to also serve areas placed some kilometers away from the BS, we decided to test essentially Line of Sight (LOS) scenarios to verify our system by mounting the receiving antenna on top of an extendable tripod and placing the system on the roof of a building, whilst the BS was on the roof of a building itself. For the non-line of sight (NLOS) cases, three typical obstacle situations can be considered: when there is a hill between the BS and the client, when there are trees and when there is vegetation. As demonstrated by [37], vegetation and foliage in particular, cause unstable radio links and affect a lot the global throughput of the system obliging the CPE to work at lower modulations. However our aim is to verify the reliability of the radio link rather than the maximum bandwidth achievable. 
The considered radio parameters are the received signal strength indicator (RSSI) and the carrier to interference plus noise ratio (CINR). The first is a measurement of the total received power of the frame preamble and is used by the subscriber station to determine the received signal level from the BS [38]. The latter represents a measure of the quality of the WiMAX signal. The higher the value of the CINR, the more throughput a link can maintain. The standard 802.16 supports the link adaptive modulation and the channel coding (AMC) and, in order to maintain a constant bit error rate (BER) of 1 part per million, it adapts to signal degradation by dropping to a lower modulation [39].

The AMC is controlled BS side and it applies the Modulation and Coding Schemes (MCS) which defines the most suitable modulation rate for current radio channel, and leads to the highest data rate possible. WiMAX mainly uses quadrature amplitude modulation (QAM) with its more powerful 64-QAM5/6 in downstream; it is optional in upstream [26]. Maximum modulation in upstream is usually 16-QAM3/4. In Table 5 the test shows no packet loss until $12.9 \mathrm{~km}$.

Table 5. WiMAX uplink modulation in LOS.

\begin{tabular}{cccc}
\hline UL Modulation & Packet Loss & CINR (dB) & AvgDistance from BS (km) \\
\hline 16-QAM3/4 & $0 \%$ & 23 & 4.5 \\
16-QAM1/2 & $0 \%$ & 15 & 7.3 \\
QPSK3/4 & $0 \%$ & 13 & 10.1 \\
QPSK1/2 & $0 \%$ & 9 & 12.9 \\
\hline
\end{tabular}

\subsection{Measurements}

As explained, the control system manages the isle providing the switch-on times (in minutes) and the absorbed currents of the lamps (in Amperes). Every control card of the lamp posts collects these data sending them to the coordinator when it requests them. After that, the coordinator control card provides to post the data on the website. To avoid data collisions, the coordinator calls the lamp posts one by one exploiting a specific identification number (ID) associated to each of them. Data collected during some autumn and winter months of 2013/14, showed the lamps absorb about 1.5 A during the activity for a period between 22.5 and $24 \mathrm{~h}$ per month.

\subsection{Comparison with a Classic Lamp Posts}

The absence of mains near the isle prevented us to making a direct comparison with a classical technology lamp post as for i.e., in [3], so we designed this comparison following two ways: in the first our lamp post (called L1) is directly compared with another (called L2), similar to the first, but without the presence sensor control, so it was always switched on during the night; in the second, we realize a simulation considering the L2 supplied by mains (this lamp post is called L3). The results are reported in Table 6.

We performed this test in February 2014 and both the lamp posts used a $18 \mathrm{~W}$ LED technology, 1550 lumen, $84 \mathrm{~lm} / \mathrm{W}$ luminous flux, powered by a solar panel and a battery. For L3 we assumed the lamp post was supplied by mains through a $12 \mathrm{~V} \mathrm{AC/DC}$ converter. 
Table 6. Current consumption and operating time of new and old lampposts.

\begin{tabular}{|c|c|c|c|c|c|c|c|c|c|c|}
\hline \multirow[b]{2}{*}{ Lamp ID } & \multicolumn{2}{|c|}{ February } & \multirow[b]{2}{*}{$\mathbf{k W h}$} & \multirow[b]{2}{*}{$\begin{array}{c}\text { Cost h } \times \text { kWh } \\
(0.200 €) \\
\end{array}$} & \multicolumn{6}{|c|}{ Plant Costs } \\
\hline & Time (h) & I (A) & & & $\begin{array}{c}\text { Battery Type } \\
\text { and Cost }\end{array}$ & $\begin{array}{c}\text { Solar Panel } \\
\text { Type and Cost }\end{array}$ & $\begin{array}{c}\text { Battery } \\
\text { Recharger }\end{array}$ & Lamp $€$ & $\begin{array}{c}\text { Power } \\
\text { Supplier }\end{array}$ & $\begin{array}{l}\text { Electronic } \\
\text { Devices } €\end{array}$ \\
\hline New Lamp (L1) & 21.36 & 1.48 & 0.367 & 0 & $5 \mathrm{~A}-16 €$ & $19 \mathrm{~W}-50 €$ & $10 €$ & 18 & 0 & 40 \\
\hline $\begin{array}{c}\text { New Lamp without } \\
\text { light sensor (L2) }\end{array}$ & 280 & 1.49 & 5.006 & 0 & $20 \mathrm{~A}-25 €$ & $80 \mathrm{~W}-220 €$ & $10 €$ & 18 & 0 & 0 \\
\hline $\begin{array}{l}\text { New Lamp without } \\
\text { presence sensor and } \\
\text { supplied by mains (L3) }\end{array}$ & 280 & 0.09 & 5.796 & 1.159 & None & None & 0 & 18 & 30 & 0 \\
\hline
\end{tabular}

Considering fixed the cost of the $\mathrm{kWh}$ of power (in Italy $\approx 0.2 €[40]$ ) and that the first and second lamp posts have no power consumption, to find the break-even we used the following formula [3]:

$$
P C_{Z}-P C_{Y}+\sum_{i=1}^{x}\left(k W h_{Z i}-k W h_{Y i}\right) \cdot C_{k W h_{i}}=0
$$

where PC is the plant cost difference between different lamp posts and it is a fixed cost; $\mathrm{kWh}$ is the number of kilowatt per hour used by the specific lamp post day by day; $\mathrm{C}_{\mathrm{kWhi}}$ is the cost of $\mathrm{kWh}$; it can change during a long period. The term $\mathrm{x}$ is unknown and represents the activity days necessary to reach the breakeven between the two different choices of lamp posts. As imaginable the first solution is always more convenient than the second, while the first becomes more convenient than the third after 56 months.

For the coordinator lamppost we need to add the cost of the WiMAX apparatus $(80 €)$, while the Internet subscription cost is not considered because it is included in a WiMAX country public service. Moreover, there is a higher cost of the PV panel and of the battery equal to $80 €$. Distributing this last cost between the five lampposts of the isle the breakeven is reached after 83 months. Obviously if the number of the lampposts of the isle is higher, the break-even will be reached earlier.

\subsection{Management of Lamp Post Faults}

In case of lamp post faults, to accelerate restore operations, the system has to inform the users as quickly as possible. To do it, the system has both a ZigBee communication control and a voltage battery one. The first checks both the breaking of the ZigBee element and the electronic card. In both cases the program shows, on its graphical interface, the problem. The system also checks the supply coming from the battery. If it goes down, a $4.5 \mathrm{~V}$ backup battery, integrated in the box, provides the necessary energy to work. The electronic card is moreover designed to check the backup battery voltage so, if this is too low, a battery fault signal will be sent to the coordinator program.

\section{Comparative Studios}

To shows the advantages of our SC application, three other analysis have been conducted. The first shows a comparison between our isle and another realized with classical technology with lamp posts without presence sensors and supplied by mains. Considering the month of Table 6 , the consumption of the classical isle composed of five lamp posts would be equal to $145.75 \mathrm{kWh}$ with an energy cost of 
$29.15 €$ and a carbon production equal to $77.25 \mathrm{~kg}$ [41]. Obviously, with our isle the cost and the production of carbon dioxide is equal to zero.

The second shows an extension of the proposed system to other two isles of lamp posts realized in the meantime. Both these isles are composed by five lamp posts and are always placed in rural areas. Again, for both, WiMAX is the only technology usable for the Internet connection. The months considered are only November and December 2014 in which the three isles were contemporaneously active. If the isles had been realized with conventional technology, the overall power consumption was about $220 \mathrm{kWh}$ with a cost of $44 €$ and a production of $116.6 \mathrm{~kg}$ of $\mathrm{CO}_{2}$. Always in this case using our system the cost and the production of carbon dioxide is equal to zero.

Considering an annual use of the three isles equals about $67,725 \mathrm{kWh}$, the total estimated savings is equal to about $13,545 €$ and a production of about $35,894 \mathrm{~kg}$ of $\mathrm{CO}_{2}$. It easy imaginable that a bigger number of isles allows one not only to increase the savings, but also to reduce the overall maintenance costs thus increasing the benefits.

Another comparison has been realized changing the scheme of the isle connecting in series eight lamp posts located $20 \mathrm{~m}$ away from each other. In this configuration, the presence sensor cards are placed at the start and at the end of the line. The overall functioning of the system is similar to the previous configuration, but, in this case, a transmission data problem surely happens. In fact, the ZigBee transmission range of XBee module is at maximum $100 \mathrm{~m}$ in LOS, so this obliges us to transform the mesh ZigBee architecture into a serial architecture where data sent by the n-lamp post, must be acquired by the n-1-lamp post, and so on up to the Coordinator. To face the problem it is necessary to modify the Monitoring Station Software creating a recursive program able to pack the data coming from the n-lamp post and send them together with data of the n-1-lamp post towards the n-2-lamp post and so on up to the Coordinator. On the other side, the requests from the Coordinator toward the secondary lamp posts have to be similarly packed and serially delivered to the lamp posts. Making these changes, the system correctly works. From an economical point of view, the general considerations made for a mesh configuration are equally valid.

\section{Conclusions}

The application of new technologies to a system, historically not the subject of much innovation, can transform it into an extremely efficient system allowing energy and money savings if compared with classical systems, as the Smart City paradigm teaches.

The example shown in this article is a clear demonstration of this thesis. An isle of lamp posts used to light a crossroads and placed far from the city where the Internet signal does not arrive, has been re-designed combining all new technologies available on the market: LEDs for the lamps, PV panels for the power supply and an intelligent management.

This last foresees an architecture that uses local sensors for intelligent lighting of the lamp, the storage of the functioning data, and their sharing by a local communication wireless mesh realized by ZigBee devices that send information to the coordinator lamp equipped with a RaspBerry-Pi card. The RaspBerry-Pi has been chosen for its low costs and for the possibility to drive also a WiMAX modem/router which allows to make the data system visible by a web site accessible by Internet also for areas very far from the city and not reached neither by the ADSL line nor by $3 \mathrm{G}$ signals. 
Some analysis and comparisons testify the validity of the adopted choices. For its reliability, simplicity and low cost, the proposed system can also be used to update existing conventional lamp posts making it a serious candidate to efficiently manage a set of sensors applicable in different fields including monitoring of energy consumption, other Smart City application and smart grids which needs to diffuse sensors and actuators to realize an efficient management of the system under control.

\section{Author Contributions}

Fabio Leccese conceived the idea of the system, all the authors realized the hardware and the software of the system. The Zigbee tests have been designed and performed by Fabio Leccese and Marco Cagnetti, while the test for the WiMAX have been conceived by Daniele Trinca and performed by all the three authors. Fabio Leccese wrote the paper.

\section{Conflicts of Interest}

The authors declare no conflict of interest.

\section{References}

1. Elejoste, P.; Angulo, I.; Perallos, A.; Chertudi, A.; García Zuazola, I.J.; Moreno, A.; Azpilicueta, L.; Astrain, J.J.; Falcone, F.; Villadangos, J. An Easy to Deploy Street Light Control System Based on Wireless Communication and LED Technology. Sensors 2013, 13, 6492-6523.

2. Tan, Y.K.; Huynh, T.P.; Wang, Z. Smart Personal Sensor Network Control for Energy Saving in DC Grid Powered LED Lighting System. IEEE Trans. Smart Grid 2013, 4, 669-676.

3. Leccese, F. Remote-Control System of High Efficiency and Intelligent Street Lighting Using a ZigBee Network of Devices and Sensors. IEEE Trans. Power Deliver. 2013, 28, 21-28.

4. Pizzuti, S.; Annunziato, M.; Moretti, F. Smart street lighting management. Energy Effic. 2013, 6, 607-616.

5. Lee, C.K.; Li, S.N.; Hui, S.Y. A Design Methodology for Smart LED Lighting Systems Powered by Weakly Regulated Renewable Power Grids. IEEE Trans. Smart Grid 2011, 2, 548-554.

6. Costa, M.A.D.; Costa, G.H.; dos Santos, A.S.; Schuch, L.; Pinheiro, J.R. A High Efficiency Autonomous Street Lighting System Based on Solar Energy and LEDs. In Proceedings of 2009 Power Electronics Conference, Bonito-Mato Grosso do Sul, Brazil, 27 September-1 October 2009; pp. 265-273.

7. Wang, Y.Q.; Hao, C.C.; Zhang, S.L.; Huang, Y.L.; Wang, H. Design of Solar LED Street Lamp Automatic Control Circuit. In Proceedings of International Conference on Energy and Environment Technology, Guilin, China, 16-18 October 2009; pp. 90-93.

8. Gungor, V.C.; Lu, B.; Hancke, G.P. Opportunities and Challenges of Wireless Sensor Networks in Smart Grid. IEEE Trans. Ind. Electron. 2010, 57, 3557-3564.

9. Nasirudin, M.A.; Za'bah, U.N.; Sidek, O. Fresh Water Real-Time Monitoring System Based on Wireless Sensor Network and GSM. In Proceedings of 2011 IEEE Conference on the Open Systems (ICOS), Langkawi, Malaysia, 25-28 September 2011; pp. 354-357. 
10. Peizhong, Y.; Iwayemi, A.; Zhou, C. Developing ZigBee Deployment Guideline under WiFi Interference for Smart Grid Applications. IEEE Trans Smart Grid 2011, 2, 110-120.

11. Al-Ali, A.R.; Zualkernan, I.; Aloul, F. A Mobile GPRS-Sensors Array for Air Pollution Monitoring. IEEE Sens. J. 2010, 10, 1666-1671.

12. Yang, Y.; Divan, D.; Harley, R.G.; Habetler, T.G. Power Line Sensornet-A New Concept for Power Grid Monitoring. In Proceedings of 2006 Power Engineering Society General Meeting, Montreal, QC, Canada, 18-22 June 2006; pp.1-8.

13. Rasin, Z.; Hamzah, H.; Aras, M.S.M. Application and Evaluation of High Power Zigbee based Wireless Sensor network in Water Irrigation Control Monitoring System. In Proceedings of IEEE Symposium on Industrial Electronics \& Applications (ISIEA 2009), Bandung, Indonesia, 4-6 October 2009; pp. 548-551.

14. Meng, X.; Xiao, S.; Xiong, Y.; Huang, H. ZigBee Based Wireless Networked Smart Transducer and its Application in Supervision and Control System for Natural Gas Gate station. In Proceedings of 4th International Conference on Computer Science \& Education (ICCSE'09), Nanning, China, 25-28 July 2009; pp. 301-306.

15. Zhang, Y.; Wang, L.; Sun, W.; Green R.C.; Alam, M. Distributed Intrusion Detection System in a Multi-Layer Network Architecture of Smart Grids. IEEE Trans. Smart Grid 2011, 2, 796-808.

16. Leccese, F.; Cagnetti, M.; Calogero, A.; Trinca, D.; Di Pasquale, S.; Giarnetti, S.; Cozzella, L. A New Acquisition and Imaging System for Environmental Measurements: An Experience on the Italian Cultural Heritage. Sensors 2014, 14, 9290-9312.

17. Chen, D.; Wang, M. A Home Security Zigbee Network for Remote Monitoring Application. In Proceedings of 2006 IET International Conference on Wireless, Mobile and Multimedia Networks, Hangzhou, China, 6-9 November 2006; pp. 1-4.

18. Max Stream Inc. XBee ${ }^{\mathrm{TM}} / \mathrm{XBee}-\mathrm{PRO}^{\mathrm{TM}}$ OEM RF Modules Product Manual v1.xAx - 802.15.4 Protocol. Available online: https://www.sparkfun.com/datasheets/Wireless/Zigbee/XBee-Manual.pdf (accessed on 21 October 2014).

19. Labiot, H.; Afifi, H.; de Santis, C. Wi-Fi ${ }^{T M}$, Bluetooth ${ }^{T M}$, ZigBee ${ }^{T M}$ and WiMax ${ }^{T M}$; Springer: Berlin, Germany, 2007.

20. Gislason, D. ZigBee Wireless Networking; Newnes: Burlington, MA, USA, 2008.

21. Digi. ZigBee RF Modules. Available online: http://www.digi.com (accessed on 21 May 2014).

22. EETIMES. ZigBee Application Note. Available online: http://www.eetimes.com (accessed on 21 May 2014).

23. ZigBee Alliance. ZigBee Application Note. Available online: http://www.zigbee.org (accessed on 21 October 2014).

24. Raspberry $\mathrm{Pi}^{\circledR}$. Applications with Raspberry-Pi Card. Available online: http://www.raspberrypi.org/ (accessed on 21 October 2014).

25. Raspberry $\mathrm{Pi}^{\circledR}$. Raspberry $\mathrm{Pi}$ Information Note. Available online: http://it.rs-online.com/web/ generalDisplay.html?id=raspberrypi (accessed on 21 October 2014).

26. Raspberry $\mathrm{Pi}^{\circledR}$. Raspberry $\mathrm{Pi}$ Tutorials. Available online: http://www.youtube.com/user/ RaspberryPiTutorials/videos (accessed on 21 October 2014).

27. Wikipedia, Raspberry Pi. Available online: http://en.wikipedia.org/wiki/Raspberry_Pi (accessed on 21 October 2014). 
28. How to Choose the Right Platform: Raspberry Pi or BeagleBone Black? Available online: http://makezine.com/magazine/how-to-choose-the-right-platform-raspberry-pi-or-beaglebone-black/ (accessed on 21 October 2014).

29. Arduino vs. Raspberry Pi Comparison. Available online: http://codeduino.com/information-and -news/hardware/arduino-vs-raspberry-pi/ (accessed on 21 October 2014).

30. Sivaneasan, B.; So, P.L.; Gooi, H.B.; Siow, L.K. Performance Measurement and Analysis of WiMAX-LAN Communication Operating at 5.8 GHz. IEEE Trans. Ind. Inf. 2013, 9, 1497-1506.

31. COMMSCOPE. SSPX310M, Argus ${ }^{\circledR}$ Quad Antenna 3300-3800 MHz, 65 ${ }^{\circ}$ Horizontal Beamwidth, Manual Electrical Tilt (Not Upgradeable). Available online: http://www.commscope.com/catalog/ andrew/product_details.aspx?id=5280 (accessed on 21 October 2014).

32. ZyXEL. HES-319M Outdoor WiMAX CPE Manual. Available online: http://www.manualowl.com/m/ ZyXEL/MAX318M/Manual/348786 (accessed on 21 October 2014).

33. UMTS World. WCDMA Link Budget. Available online: http://www.umtsworld.com/technology /linkbudget.htm (accessed on 21 October 2014).

34. WiMAX FORUM. Technical Specifications. Available online: http://www.wimaxforum.org/ resources/technical-specifications (accessed on 21 October 2014).

35. Jutasolar. CMP12 JUTA Datasheet. Available online: http://www.jutasolar.com/ (accessed on 21 October 2014).

36. IEEE. IEEE Std 802.16.1-2012. Available online: http://ieeexplore.ieee.org/xp1/mostRecentIssue.jsp? punumber $=6297411$ (accessed on 21 October 2014).

37. Ota, K.; Matsue, H.; Miyazawa, S.; Nanamatsu, S.; Hirata, Y.; Hasui, A.; Yamazaki, M.; Namera, T.; Fukui, H.; Harvey, M.; et al. Link Budget Analysis and Field Experiments on Mobile WiMAX System in Azumino City. In Proceedings of 2011 IEEE Global Telecommunications Conference, Houston, TX, USA, 5-9 December 2011; pp. 1-5.

38. Keysight Technologies. RSSI (8021.16 OFDMA). Available online: http://rfmw.em.keysight.com/ wireless/helpfiles/89600B/WebHelp/subsystems/80216ofdma/Content/ofdma_symtblerrdata_rssi. htm (accessed on 21 October 2014).

39. Pidutti, M. Design How-To 802.16 Tackles Broadband Wireless QoS Issues. Available online: http://www.eetimes.com/document.asp?doc_id=1272053 (accessed on 21 October 2014).

40. Quale Tariffa. Quanto costa un kWh con Enel Energia? Available online: http://www. qualetariffa.it/quanto-costa-un-kwh-con-enel-energia/ (accessed on 21 October 2014).

41. Green. Green Jazz. Available online: http://www.rockhaus.it/berchidda\%20rapporto\%20co2.htm (accessed on 21 October 2014).

(C) 2014 by the authors; licensee MDPI, Basel, Switzerland. This article is an open access article distributed under the terms and conditions of the Creative Commons Attribution license (http://creativecommons.org/licenses/by/4.0/). 